Max-Planck-Institut für demografische Forschung

Max Planck Institute for Demographic Research

Konrad-Zuse-Strasse 1 - D-18057 Rostock - GERMANY

Tel +49 (0) 3812081 - 0; Fax +49 (0) 3812081 - 202;

http://www.demogr.mpg.de

MPIDR WORKING PAPER WP 2011-005

FEBRUARY 2011 (REVISED JANUARY 2012)

\title{
Public Health, Poor Relief and Improving Urban Child Mortality Outcomes in the Decade Prior to the New Deal
}

Jonathan Fox (fox@demogr.mpg.de)

This working paper has been approved for release by: Mikko Myrskylä (myrskyla@demogr.mpg.de), Head of the Max Planck Research Group on Lifecourse Dynamics and Demographic Change.

(C) Copyright is held by the authors.

Working papers of the Max Planck Institute for Demographic Research receive only limited review. Views or opinions expressed in working papers are attributable to the authors and do not necessarily reflect those of the Institute. 


\title{
Public Health, Poor Relief and Improving Urban Child Mortality Outcomes in the Decade Prior to the New Deal ${ }^{1}$
}

\author{
Jonathan Fox
}

\section{Max Planck Institute for Demographic Research January 2012}

\begin{abstract}
This paper examines the effectiveness of the public health education and poverty relief programs prior to the New Deal. Prior researchers have speculated these programs contributed to the declining mortality rates during the $1920 \mathrm{~s}$, but have been unable to econometrically estimate their impact across a large set of cities. Data on municipal health education and social insurance expenditures is used to separately estimate how effective each of these programs were at reducing infant and child mortality. The effects are identified using the within variation for a panel of 68 cities over 10 years, with estimates suggesting that it was primarily spending on health education which led to lower infant and child mortality during the 1920s. Additionally, for both the infant and child age groups, the education programs required a two-year lag to generate an effect. Fixed effects estimates indicate that 1 dollar of per capita public health education spending in year $t$ translated to about a 0.93 unit drop in the infant mortality rate in year $t+2$, and about a .02 unit drop in the crude death rate for children aged 1 to 4 . In terms of actual municipal expenditures during this period, these estimates show that cities in the top quartile of public health education spending experienced an additional 2.4 unit average annual decline in their infant mortality rates than did cites in the bottom percentile. JEL codes I18, I38, and N32
\end{abstract}

\footnotetext{
${ }^{1}$ Contact: Jonathan Fox, jfox@ demogr.mpg.de. Max Planck Institute for Demographic Research, Konrad-ZuseStrasse 1, 18057 Rostock, Germany. +49(0)381 2081-192. The author would like to thank Price Fishback and Paul Rhode for providing access to their data, as well as Ronald Oaxaca, Manuela Angelucci, Kei Hirano and Mikko Myrskylä, as well as participants at the 2009 All UC Conference in Economic History for all of their helpful comments and suggestions. This research has been funded by the Economic History Association and the National Science Foundation grant number SES 0921186. All errors are the author's own.
} 


\section{Introduction}

During the early 20th century, infant and child mortality declined substantially both in urban and rural areas. Prior to 1910, for every 1,000 babies born in the United States, 165 died before their first birthday (Newmayer 1911). However by 1920, infant mortality fell to about 85 deaths per 1,000 live births, and by 1930 dropped to 65 . Child mortality experienced similar declines.

These declines in U.S. infant and child mortality began as early as 1850 . Estimates for the white population indicate that the infant mortality rate was halved in the U.S. between 1850 and 1900 (216.8 to about 100 ), and continued falling to about 80 deaths per 1,000 live births by 1920 (Haines 2000). However, there still existed substantial differences across cities and population groups. Foreign born and minority populations generally experienced far worse outcomes, as immigrant families from the Eastern European countries had infant mortality rates double that of the native white populations (Dempsey 1919, Duke 1915, Hughes 1923). And mortality trends differed across areas as well. Boston, MA had an infant mortality rate over 100 in 1920, but this improved to just below 70 by 1930 . By contrast, Portland, OR had already achieved an infant mortality rate below 60 by 1920. Its infant mortality rate improved to about 40 by 1930 .

Municipal sanitation and water projects explain a substantial part of this decline and the differences in outcomes in the early $20^{\text {th }}$ century (Cutler and Miller 2005, Ferrie and Troesken 2008), but there is still much variation left unexplained in large urban areas during the 1920s. For this decade, nearly all major cities already had clean water and sanitation, yet infant and child mortality outcomes continued to diverge across the different cities. One reason for why certain cities experienced greater declines in infant and child mortality was improvements in the education of the population about simple health procedures such as hand washing and boiling water. This paper investigates these early public health education programs in the large U.S. municipalities and estimates their influence on the declining infant 
mortality rate and scaled crude death rate (deaths per 10,000 persons) for children aged 1 to 4. This will inform on the potential causes behind the health transition that occurred in the United States in the early twentieth century. Additionally, the educational programs in the state, municipal, and county health departments were much more cheaply implemented than the large scale public works projects developed in the cities in the decade prior. Evaluating the success of these programs informs on an inexpensive path to improving health and mortality outcomes. In settings where locales have limited access to the necessary capital to build the sanitation and filtration infrastructure, these programs are potentially low cost ways to reduce mortality while waiting to build the larger public works. Or, as was the case in the United States during the 1920s, they may also be low cost and complementary ways to lower mortality even after the works are built.

While the U.S. experienced great reductions in infant and child mortality in the first few decades of the twentieth century, there was a great deal of inequality in the improvements. The adjustments were uneven, and there existed substantial variation across locations in the mortality trends. The great variation across areas in public program expenditures may help explain the differential improvements. Before the New Deal of the 1930s, few federal welfare or public health programs existed and those that did were either investigative bodies or mandated states to distribute benefits to certain classes of people. Health and welfare spending decisions were made at the state, city or county level. This paper examines the decade of the 1920s to estimate the effectiveness of state and local public health and poverty assistance programs at saving the lives of children without confounding them with the large-scale changes associated with the New Deal. ${ }^{2}$

The concurrence of the declines in child and infant mortality with the growth of public health work suggests the two related. Many believe that the public health education

\footnotetext{
${ }^{2}$ The analysis is constrained to those years after 1923 because the level of financial detail necessary is not available between the years 1920-1922
} 
played an important role in improving outcomes (Ferrell et al 1932, Vincent 1921, Blackburn 1927, Ewbank and Preston 1989, Preston and Haines 1991), although there has yet to be an econometric estimate of their impact across the different municipalities. Preston and Haines (1991) attribute a lack of know-how rather than a lack of resources as being primarily responsible for poor health outcomes in the late nineteenth and early twentieth centuries. In summarizing their points regarding the effects of behavioral changes encouraged by these early public health education programs in the first few decades of the United States, Ewbank and Preston state that "While the case is hardly air-tight and perhaps can never be made so, we believe this evidence suggests that personal health practices, especially those which reduced children's exposure to pathogens, were a major contributor to the declines in infant and child mortality" (Ewbank and Preston 1989, page 143).

This sentiment was echoed by public health experts and administrators during the 1920s as well, and supported with anecdotal evidence and case studies. Grace Abbot, chief of the Children's Bureau, wrote in an article for the American Journal of Public Health that "The instruction of mothers through infant-welfare centers, public health nurses, and population bulletins as to the care of children, the value of breastfeeding, the importance of consulting a doctor upon the first evidence of disease, everywhere brought substantial decreases in deaths (Abbott 1922)." And a statistician at the Metropolitan Life Insurance Company emphasized the importance of public health education to an even greater extent saying that "No field of public-health activity would repay larger dividends to the community than the widespread dissemination of health education" (U.S. Public Health Service 1923).

Researchers and writers used poor maternal and child health outcomes to advocate the importance of hygiene (e.g. Brown 1923) and studies of children demonstrated the positive effects health education could have. An example of this is an experiment conducted by an MIT biology and public health professor during the 1920s (Turner 1921). The experiment 
involved estimating the effect of weekly health education lectures on the health outcomes for a set of school children, as measured by normal weight gain. The researcher stratified students into treatment and control groups, and found that those students subject to the health education curriculum experienced greater health improvements relative to the control.

Without data on the state and local health and education programs, modern researchers studying determinants of the early twentieth century mortality decline have either controlled for the influence of the public health education movement using the timing of major water and sanitation installments in a difference-in-differences model (Cutler and Miller 2005), year and geography fixed effects (Troesken 2004) or inferred its effects by comparing differential mortality trends across occupational groups (Ewbank and Preston 1989). This paper uses data on municipal health education, outdoor care of poor spending and spending on charity for children and mothers to estimate separately each of their effects on infant and child mortality. The following section describes each these programs and how it each may have helped to improve health outcomes.

\section{Public programs and improving outcomes}

Public health and poverty assistance programs first started gaining support in the early 20th century as birth and death registration areas grew. As these areas expanded, data collected on births and deaths were gathered on a more consistent basis and became more reliable for comparisons. Demographers began to have a clearer picture of the how poorly children fared in the United States compared with other developed countries, and public health advocates began to question if perhaps the U.S. could possibly do better (Newmayer, 1911). Research by scientists such as Louis Pasteur in the late 1800s on the relationship between sanitation and health, and by Paul Karrer on the importance of vitamins and nutrients in the early 1900s offered ways in which these issues could be addressed. Public 
health education, by helping to disseminate this knowledge regarding germs and vitamins, had the opportunity to improve health outcomes and lower mortality.

Cities differed in their implementation of the public health programs during the 1920s, but they typically included lectures, conferences, pamphleteering, bulletins, infant hygiene stations and milk stations (U.S. Public Health Service 1923). They generally advocated for increased use of breast feeding, smaller families, hand washing, boiling water and proper nutrition during pregnancy. Many cities set up programs to inspect school children for medical issues. Detroit, MI exemplified this, conducting annual medical inspections by physicians for all of the children in its public and parochial schools (U.S. Public Health Service 1923). In Detroit and other cities, inspections typically included examining the heart, lungs, eyes, ears, nose and throat, and sometimes included dental exams. Occasionally they were administered by physicians, as was the case in Detroit, but more commonly a nurse conducting the examination. Activities at the infant welfare stations also varied considerably across the cities, but generally consisted of the supervision of expectant mothers and new infants, lectures, baby shows and the distribution of free literature (U.S. Public Health Service 1923).

Although it is not known for certain, a portion of the funds for these municipal public health activities were likely provided for by the Promotion of the Welfare and Hygiene of Maternity and Infancy Act passed in 1921. This act, more commonly known as the Sheppard-Towner Act, constituted the first federal public health program and was primarily focused on health education. Federal matching grants were distributed to states with specific instruction in their use. Recipients were prohibited from using the money for any form of capital improvements, purchases or stipend payments (U.S. Children's Bureau 1924). Instead, the money was intended to pay for the operation of health centers to instruct mothers 
in hygienic ways and to distribute pamphlets to new mothers about how best to care for their baby (Thompson 1921).

The Sheppard-Towner grants consisted of an initial \$5,000 grant and additional money in the form of matching grants. States choosing to accept Sheppard-Towner appropriations were required to designate a maternity and infant hygiene division within their health department to disburse the funds. Most states accepted some level of the available federal Sheppard-Towner funds, however many only took a portion and Connecticut, Illinois, and Massachusetts chose not to participate at all (Moehling and Thomasson 2010).

For most areas participating in the program, it is not fully known how exactly the Sheppard-Towner money was spent. However, the State of New York in 1924 offers a glimpse into how these monies were distributed. Between July 1, 1923 and June 30, 1924, the New York State Health Department spent a total of $\$ 63,415.30$ on Sheppard-Towner related activities (New York State 1924). Almost $\$ 25,000$ of this was spent on the salaries for the individuals employed by the state division of Maternity, Infancy, and Child Hygiene. Additional funds were allocated to the printing of bulletins and pamphlets and the postage associated with distributing them. And the funds were also used to employ a set of nurses who traveled to the different municipalities, engaging in lectures, demonstrations, and consultations with mothers of infants and preschool children. So, while it is not known to what extent Sheppard-Towner appropriations showed up in the municipal expenditures, it is likely they were present.

Through the types of activities described above, municipal governments in the 1920s U.S. may have helped to improve the behaviors of their population. The discoveries of Pasteur and Karrer created an opportunity for public health education to have an effect, so the dissemination of this knowledge to new and expectant mothers may have improved infant and child mortality during the decade. 
Other municipal investments which may have helped effectuate declining infant and mortality in the 1920s include the mothers' pension and charity for children programs, as well as the outdoor care of poor programs. These programs originated in the decade prior, however persisted through the 1920s and so may also be related to the improving outcomes.

The mothers' pensions programs grew out of an effort to improve the wellbeing of children and mothers, as advocacy groups for these populations influenced politicians to pass the legislation (Skocpol et. al, 1993). For the areas in which mothers' pensions were implemented, it consisted of transfer payments to mothers who had been widowed. Charity directed towards children supported children residing in almshouses. For the purposes of this study, spending through these two programs is combined into a single measure of spending on "charity for children and mothers."

Like the mothers' pensions, outdoor care of poor first began to arise during the 1910s and grew through the 1920s and early 1930s when it was replaced by the federal social security programs in the New Deal. Outdoor care of poor differed in its administration across cities, but typically involved relief to individuals or families that due to unemployment, illness, accident, or other reasons, were temporarily dependent. It also sometimes involved the giving of aid more or less permanently, when it seemed desirable to keep a family together instead of scattering its members among institutions (Smith 1932, Lancaster 1937). It was under this category that cities distributed relief to individuals unemployed during the Great Contraction of 1929. Outdoor care of poor is then a social insurance program, administered at a local level and before the large scale federal social security programs. To the extent that a negative economic shock is associated with an increase in mortality, this program may help to offset that. For families eligible, it can help improve maternal and infant nutrition, thereby improving health outcomes. 
Using information on these three different public programs, one type education, one type transfer payment, and one type social insurance, this paper separately estimates the role each played in reducing mortality during the 1920s and early 1930s. Additionally, it does so for a diverse set of urban areas in the U.S. Because of this diversity, not all of the included municipalities participated in the Birth Registration Area for the entirety of the panel. In constructing a measure of infant mortality, it is important to control for fertility since the number of infant deaths is a function of the number of births. If any of the above programs are associated with changes in fertility, which the public health education spending likely is (Fox, Myrskyla 2011), then failing to control for fertility could lead to a spurious effect. For those areas part of the Birth Registration Area, this is a simple matter. However, it becomes more complicated when information on births is not available. In order to include these areas, which tend to be concentrated in the Southeast and Midwest, it is necessary to estimate the number of births.

\section{Estimating births where no data exist}

While most states and all of the large urban areas were recording births by 1920, only a portion of the areas were recording births. Figure 1 displays the Birth Registration Area (BRA) as it stood in 1920, along with those large urban areas which were recording deaths. Immediately evident is the absence of areas in the Southeast and Midwest recording births, but for which information on deaths is available. Focusing only on the Birth Registration Area would eliminate cities in states such as Texas, Alabama and Georgia. This would miss an important part of the variation in the level of public program investment, since these areas tended to be lower in their expenditure levels and higher in their crude infant and child death rate levels. In an effort to include these areas in the analysis for all ten years of the panel, this 
section details the method of birth imputation to estimate the infant mortality rate for areas not part of the BRA.

For those areas part of the BRA, calculation of the infant mortality rate is straightforward. Namely for city $i$ in year $t$,

$$
I M R_{i, t}=\frac{D_{i, t}^{0-1}}{B_{i, t}} * 1,000
$$

Where $I M R_{i, t}$ is the infant mortality rate in city $i$ and year $t, D_{i, t}^{0-1}$ is the number of infant deaths in city $i$ and year $t$ and $B_{i, t}$ is the number of births recorded in city $i$ and year $t$. For those areas not part of the BRA, the number of births in city $i$ and year $t$ is estimated using the fertility rate in year $t$ across all those cities both part of the Birth Registration Area and over 100,000 persons in 1920, and the female population for city $i$ in year $t$. Made explicit this is,

$$
\hat{B}_{i, t}=\frac{B_{s, t}}{F p o p_{s, t}^{15-44}} * F_{p o p}^{15-44}
$$

Where subscript $s$ denotes the set of cities part of the BRA and over 100,000 persons in 1920 . So, $B_{s, t}$ is the total number of births occurring in year $t$ within the set of cities $s, F p o p_{s, t}^{15-44}$ is the female childbearing population (population aged 15 to 44) across the set of cities $s$ in year $t$, and $F$ pop $p_{i, t}^{15-44}$ is the female childbearing population in city $i$ and year $t$.

To evaluate the ability of $\hat{B}$ to approximate the levels and changes in births for each of the cities, Figure 2 plots the two series for those cities part of the 1920 BRA and over 100,000 persons. Appendix Table A3 details those cities included. From Figure 2, $\hat{B}$ tends to slightly overestimate changes in the total number of births, but does a good job reflecting year to year changes. The two values are also highly correlated, with a correlation coefficient of .9964 and a large amount of the variation in $B$ being explained by $\hat{B}$. To determine this 
latter value, $\hat{B}$ is regressed on $B$, with the results given in Table 1 . The coefficient on $\mathrm{B}$ hat reflects its slight overestimation of births, with an estimate of about 0.87 . More importantly, however, is the $R^{2}$, which comes in at about 0.993 . Because $\hat{B}$ probably does slightly worse at estimating births outside of the Birth Registration Area, it will be important to make sure any estimation results hold for the set of BRA cities using the standard Infant Mortality Rate.

After estimating births for areas in which that data does not exist, infant mortality is estimated as the following:

$$
I M R_{i, t}^{*}=\left\{\begin{array}{l}
\frac{D_{i, t}^{0-1}}{B_{i, t}} * 1,000 \text { if } \text { city }_{i} \in B R A \\
\frac{D_{i, t}^{0-1} * 1,000 \text { if } \text { city }_{i} \notin B R A}{\hat{B}_{i, t}}
\end{array}\right.
$$

This $I M R_{i, t}^{*}$, along with the crude death rate for children aged 1 to 4 , will then be the outcomes of interest in studying the effects of public health, charity for children and mothers and outdoor care of poor during the 1920s.

\section{Data}

The panel dataset used to estimate the relationship between the outcomes of interests and the municipal public program investments is composed of annual information from 68 cities with populations over 100,000 during the period 1923-1932. Those years were chosen both for data availability reasons and to eliminate the effect of any New Deal programs enacted after 1932. ${ }^{3}$ City financial data, including spending on health, charity, schools and hospitals, was collected from the Financial Statistics of Cities volumes published by the Department of Commerce. Per capita summary statistics adjusted to 2007 dollars for each of the spending

\footnotetext{
${ }^{3}$ Fishback, Haines, and Kantor (2007) examine the time period from 1929 through 1940 to examine the role of the New Deal in influencing infant deaths, non-infant deaths and births.
} 
variables are given in the top panel of Table 2. Population data were collected from the decennial censuses and interpolated for the intercensal years.

The three municipal financial variables of interest are the spending on public health education, spending on charity for children and mothers and spending on outdoor care of poor. Spending on public health education includes spending on the medical inspection of school children and spending for education about proper hygiene, milk preparation techniques and other things that could be done to conserve child life. Money distributed under the "medical inspection for school children" category helped pay for physician and nurse visits to distribute information and perform physical examinations. School children were not treated, but their parents were informed if any defects were found. Spending on charity for children and mothers includes spending on mothers' pensions, funding for almshouses and orphanages and other charitable spending for children. Outdoor care of poor typically involved relief to individuals or families that due to unemployment, illness, accident, or for perhaps some other reason, were temporarily dependent. It also sometimes involved the giving of aid more or less permanently, when it seemed desirable to keep a family together instead of scattering its members among institutions. Adjusted to 2007 dollars, an average city in the dataset spent about $\$ 3.17$ per person on public health education, about $\$ 4.70$ on charity for children and mothers and about $\$ 11.56$ on outdoor care of poor. Every city in the sample invested at least some level of expenditures in the public health education programs. Conversely, 16 cities invested no money towards charity for children and mothers and two cities in the sample had periods of time for which outdoor care of poor expenditures were equal to zero. Other types of municipal spending are also included. These categories of expenditures are "Other charity," "Hospitals," and "School expenditures per enrolled student." 
Mortality and data was entered from the Mortality Statistics volumes, also published by the Department of Commerce. The mortality data was combined with fertility information from the Birth, Stillbirth and Infant Mortality Statistics volumes to construct $I M R^{*}$ and the crude death rate for children aged 1 to 4 . Figures 3 and 4 plot each of these mortality rates for the different cities in the panel. First noticeable from Figure 3 is the wide variation in infant mortality across the cities. This was true at the start of the panel, with cities such as Seattle, WA, San Francisco, CA and Minneapolis, MN having infant mortality rates below 60 in 1923, while New Bedford MA, Lowell, MA, and Richmond, VA all had infant mortality rates over 100. With the exception of a couple of shocks in 1926 and 1928, infant mortality for most of the cities declined through the 1920s. Additionally, there is some slight compression in the infant mortality rates across the cities through the 1920s and early 1930s. However, there were still a few cities that fared poorly into the 1930s. San Antonio, TX had the highest infant mortality within this sample through the 1920s, and kept its pole position through the early 1930s. Memphis, TN and Nashville, TN also fared poorly relative to the average at the end of the decade, as did New Orleans, LA.

Comparing figures 3 and 4 , it is evident that there is much more variation in the infant mortality rates than in the crude deaths rates for children aged 1 to 4 . Like the infant mortality series, child mortality also tended to decline through the 1920s and 1930s, and exhibited some compression in the rates across areas. However there still existed differences across cities which persisted through the early 1930s. San Antonio continued to be a leader in high mortality rates across the group of cities. The improvements in infant and child mortality across time, and the differing trends across cities is particularly interesting given that, except for Milwaukee, every city in the sample had developed their water and sewer systems prior to 1923 . 
To explore whether differences in investment in the different types of public programs may have contributed to the declines and compression of the trends, Figure 5 plots meandifferenced infant mortality trends for sample cities at the top and bottom of the spending distributions for each of the different public programs. 5a plots these for groups of cities at the top and bottom quartiles of aggregate health education spending between 1923 and 1932 . The trends suggest some level of selection, where cities which spent a relatively large amount on health education generally had infant mortality rates greater than other large cities in the early 1920s. By 1932 these cities were performing better than the average. ${ }^{4}$ Figure $5 \mathrm{~b}$ plots these mean-differenced trends for cities at the top and bottom quartiles of spending on charity for children and mothers and $5 \mathrm{c}$ does this for cities at the top and bottom quartiles of outdoor care of poor spending. From Figure 5b, it does not appear that investments in the charity for children and mothers programs altered the infant mortality trajectories in the different cities. From $5 \mathrm{c}$, however, outdoor care of poor appears to have had a strong effect. As was with health education, cities with higher infant mortality rates tended to spend more on outdoor care of poor, but their outcomes improved relative to the average during the 1920 s and early 1930s. The opposite was the case for cities spending little on outdoor care of poor. Cities in the bottom quartile had lower infant mortality relative to the average at the beginning of the 1920s, however were performing much worse by the end of the decade.

Figure 6 examines this question with respect to death rate for children aged 1 to 4 . A similar story occurs with the older age group. Cities that spent more on health education and outdoor care of poor between 1923 and 1932 on average experienced worse death rates in the early 1920s, while cities that spent less on average had child death rates below the mean. However, by 1926, the positions of the bottom and top quartiles had reversed. Figure $6 \mathrm{~b}$ does suggest that charity for children and mothers may have had an impact for this older age

\footnotetext{
${ }^{4}$ Plotting the actual infant mortality rate for the top and bottom quartiles for the subset of cities with birth data reveals similar patterns.
} 
group. By 1923, cities which invested more in charity for children and mothers had child death rates slightly lower than the average, while cities which spent less on charity for children and mothers had child deaths relatively higher.

Figures 5 and 6 suggest that in the case of both small children and infants, spending on public health education and outdoor care of poor helped to improve mortality outcomes through the 1920s and early 1930s. However, they also suggest that there was selection in which cities chose to invest more. A city's demographic structure, its religious structure, its preference for health, or some other unobserved factor correlated with both mortality and public program investment could confound efforts to establish a relationship between any of the three programs of interest and changes in infant and child mortality over time. To account for this, other data in addition to that collected from the Financial Statistics of Cities volumes is necessary.

Personal income information is unavailable at the city level prior to 1940 , so average annual earnings from the manufacturing sector are used to proxy for it. These are obtained from the Biannual Census of Manufactures volumes. Using manufacturing wages in the different cities will help control for differences in economic conditions that may confound the relationship between outdoor care of poor and mortality. From Table 2, average manufacturing wages per worker, adjusted to 2007 dollars were about $\$ 15,422$. In nominal dollars, this was close to the income of $\$ 1,500$ seen as the middle-class threshold by child advocates during the 1910s and 1920s (Duke 1915). There is some concern that higher levels of manufacturing in a city lead to higher levels of pollutants emitted, thereby increasing mortality. The proportion of adults (aged 21 and over) in manufacturing is used to control for this relationship between economic activity and mortality, first established by Ruhm (2000). On average, a city in the sample had about 17.5 percent of its adults employed in 
manufacturing jobs, although this reached as high as 51 percent for areas such as Fall River, MA and New Bedford, MA.

To control for differences in the distribution of income, the number of tax returns filed as a proportion of the population was collected from series published by the U.S. Bureau of Internal Revenue between 1923 and 1932. This gives the number of jointly filing couples in each city with incomes above $\$ 5,000$ (about 60,000 2007 dollars), and individual filers over $\$ 2,000$. Typically only about 6.6 percent of the population in the different cities filed taxes. The city with the highest proportion of filers was Los Angeles, with over a fifth of its population filing returns in 1923.

The demographics of a city are also possibly correlated with both investments in the different public programs and child and infant mortality. The foreign born population generally had much higher fertility than did the native population, and also typically experienced worse health and economic outcomes (Duke 1915, Dempsey 1919, Hughes 1923). To control for changes in the population structure and other possible confounding demographic variables, municipal demographics were collected from the decennial census and interpolated for the intercensal years. These include information on population density, minority concentrations, and literacy rates. The minority concentrations are specific to the female child-bearing population in each of the different cities. Birmingham, AL had the largest relative black population, and New Bedford, MA had the largest relative foreign born population.

\section{Econometric model and results}

From the analysis in the above data section, there is likely some selection between the extents to which cities chose to participate in the different public programs and their starting level of mortality. Due to this, estimates from an ordinary least squares regression would be biased. Thus, it is important to control for unobserved factors that potentially influence both 
mortality and the spending on public programs in the different municipalities. Assuming these unobserved factors do not change over the course of a decade, it is possible to identify the relationship between the three public programs of interest and infant and child mortality.

\subsection{Choosing a lag structure for public program expenditures}

An issue related to estimating this relationship which has not yet been discussed is the appropriate lag structure for the analysis. In the case of infants, anything that affects fetal health during pregnancy will affect infant mortality. Shocks to nutrition, stress, or weather can all affect maternal health, thus affecting the probability of infant death. So for public health education, charity for children and mothers and outdoor care of poor programs, a lag of one or two years may be the most appropriate in estimating their relationship to infant mortality. Additionally, at least in the case of the public health education programs, it may take some time for the information delivered to have an effect. A mother who received information on the importance of nutrition, hand washing and breast feeding in the autumn of some year may not be able to significantly alter the outcomes of a child who was born in the spring. That information may instead be of more benefit to children born in the future. To investigate which type of lag structure should be used in the estimating equation, a model including the distributed lags for each of the different programs, along with city and year fixed effects is estimated. The estimates from this distributed lag model are given in Table 3.

In the case of the infant mortality model, current year spending in any of the different programs had no estimated effect on a city's infant mortality rates. In the case of the public health education and charity for children and mothers programs, only the second year lags had statistically significant coefficients. For the public health education programs, this suggests it did take some time for the distributed knowledge to have an effect. The estimated coefficient on the second lag of spending on charity for children and mothers is positive. 
This is a somewhat strange result, and indicates that it will be important to control for covariates such as the foreign born population and income in the analysis whose omission may be causing bias. In terms of the outdoor care of poor spending, it appears the first lag is the most important in generating an effect.

Interestingly, the lags which were important in the infant mortality equation in general remained important in the equation for children aged 1 to 4 . None of the coefficients are statistically significant; however their magnitude provides some guidance in the choice of the lags. For expenditures on public health education, it again seems that it takes a two year period of time to generate an effect. This is also the case for outdoor care of poor. For charity for children and mothers, the distributed lag model does not give much information, however it seems that current year expenditures are the most important. These models give direction in the choice of the lags, however, because they omit other covariates controlling for factors such as the demographic composition of a city or other social expenditures, they are not the final say in which lags should be included. Thus, it will also be important to check whether any of these different lags provide better explanatory power once the other covariates are included.

\subsection{Estimating equation for infants}

Besides expenditures on public health education, outdoor care of poor and charity for children and mothers, the other covariates which will be part of the estimating equation include expenditures on charity not directed towards children and mothers, hospitals, and schools. To control for income, average manufacturing earnings are included, as are the proportion of tax filers in a city and the proportion of adults working in manufacturing. The demographic controls include the proportion of the childbearing population which was black, the proportion which was foreign born, and the percent of illiterate persons over the age of 
ten. City population density is included, since during this period of time there remained an urban death penalty for densely population areas. The number of months of drought is also included to control for adverse environmental conditions. The lag structure for each of these variables was chosen based on which was likely to influence conditions during pregnancy and which was likely to only influence conditions after birth. ${ }^{5}$ The estimating equation for infants is given as:

$$
I M R_{i, t}^{*}=\beta_{1} P H E_{i, t-2}+\beta_{2} O C P_{i, t-1}+\beta_{3} C C M_{i, t-2}+\mathrm{BX}+\gamma_{1} C_{i}+\gamma_{2} Y_{t}+\varepsilon_{i, t}
$$

Where $I M R_{i, t}^{*}$ is the estimated infant mortality in city $i$ and year $t$. As mentioned above, for those cities part of the Birth Registration Area (see Table A4 for the date each joined), IMR $R_{i, t}^{*}$ is the actual infant mortality rate. However, for areas which did not record births, it represents the ratio of infant deaths to an estimated level of births. ${ }^{6}$ The appendix contains an analysis of the model limited to only those cities part of the BRA. $P H E_{i, t-2}$ is the second lag of public health education spending occurring in city $i .^{7} O C P_{i, t-1}$ is the amount of prior year per capita outdoor care of poor spending in city $i$ and $C C M_{i, t-2}$ is the second lag for spending on charity for children and mothers. ${ }^{8}$ This latter variable includes spending on mothers' pensions, spending on almshouses and orphanages and other poverty relief spending directed towards children. $\mathrm{B}$ is a vector of coefficients for the matrix $\mathrm{X}$, which includes all of the other included covariates. Second year lags are given to other charitable spending,

\footnotetext{
${ }^{5}$ Changes to the lag structure for the included covariates did not significantly affect the coefficients for the three public programs of interest

${ }^{6}$ Appendix section A1 contains an analysis of the model limited to only those cities part of the BRA.

${ }^{7}$ The equation was also estimated using current year public health education spending and the 1 year lag of public health education spending, but the second year lag continued to have the strongest effect even after the covariates were included.

${ }^{8}$ The other lags were also estimated for these variables as well, but as was the case for public health education expenditures, the findings from Table 3 continued to hold through the inclusion of the covariates.
} 
manufacturing wages, the proportion of adults (over 21) employed in manufacturing, the proportion of tax filers in a city and the number of months of drought occurring in the state. Current year variables include in $\mathrm{X}$ are expenditures on hospitals, expenditures on schools, and the demographic variables percent black, percent foreign born, percent illiterate, and a city's population density. The errors are assumed to have mean zero, conditional on the covariates in the mortality equations and defined as the unobserved characteristics affecting mortality in city $i$, year $t$ for each of the different age groups. These are clustered at the Census region level. $C_{i}$ and $Y_{t}$ are vectors of city and year effects, respectively. This model does not include a city-specific trend variable, simply because it controls for too much of the variation in the different public program expenditure variables to make precise identification of the coefficients possible. Additionally, if investment in public health education affected the mortality trend within a city, then controlling for that trend would remove a potential path of influence. ${ }^{9}$

The year fixed effects are used to control for nationwide, annual shocks associated with macroeconomic policy, national optimism, or other factors common across the sample cities in a specific year. The city fixed effects control for unmeasured factors that varied across the cities but not through time. An important factor that fits this definition is the quality of water treatment and sanitation infrastructure. In 66 of the 67 cities there were no major capital improvements to the water treatment and sanitation infrastructure over the period; therefore, absent depreciation, the quality of the infrastructure over the period should be time-invariant in each city. ${ }^{10}$ Better infrastructure would have tended to reduce death rates, implying a negative relationship between the sanitation and water treatment facilities and death rates. If the fixed effects to control for these major facilities were left out, the sign

\footnotetext{
${ }^{9}$ Appendix section A2 contains an analysis of the model when including a city-specific trend variable, as well as calculations of the proportion of variance controlled for by the fixed effects and trend variable.

${ }^{10}$ Milwaukee added a water treatment plant in 1926. Estimations excluding Milwaukee from the analysis yielded very similar coefficient estimates
} 
of the omitted variable bias will be determined by the relationship between sanitation and water treatment and a city's choice about public health education. If cities with better sanitation and water treatment infrastructure saw them as substitutes for public health education, they would have spent less on public health education. The combination of the negative relationship between infrastructure and death rates and the negative correlation between infrastructure and health education would impart a positive bias to the public health education coefficient. On the other hand, if cities with better infrastructure saw the public health education as a complement to the infrastructure, they might have invested in more public health education. This would then lead to a negative bias for the coefficient of public health education in the regressions without city fixed effects.

The coefficient of the poverty relief variable might also be affected by the quality of sanitation and water treatment infrastructure. If areas with better sanitation infrastructure were areas with more poverty relief spending, the combination of this positive correlation and the negative correlation between infrastructure and death rates would have led to a negative omitted variable bias for the coefficient on poverty relief. ${ }^{11}$ Given this, using a fixed effects model is likely necessary to obtain unbiased coefficient estimates.

Table 5 presents estimates from the above the infant mortality equation. Column 1 gives the estimated relationship between the different public programs and $I M R^{*}$ without inclusion of any of the covariates. Column 2 includes the full set of covariates. Comparing the public health education and poverty relief coefficients columns 1 and 2 , it is first clear that differences across municipalities and time explain a large proportion of the variation in mortality during this period. The change in $R^{2}$ between the two columns is very small.

\footnotetext{
${ }^{11}$ After controlling for income, income distribution, various types of city spending, and city and year fixed effects, much of the potential endogeneity has been controlled for. In the possibility that some remains, attempts at different instruments have been made. However thus far, a variable sufficiently correlated with health or poverty spending to get past weak instrument problems has not been found. Some of the potential instruments tried and shown little strength are state-level voting patterns, the timing of a state's women's suffrage enactment, and whether or not a state chose to participate in the Sheppard-Towner Act.
} 
However, many of the covariates included are statistically significant and contain important information.

Once the full set of covariates and fixed effects are included, public health education and outdoor care of poor spending were associated with reductions in the infant mortality rate. Additionally, the negative relationship was much stronger for public health education spending. An additional dollar of per capita public health education spending is connected with about a 0.93 point reduction in a city's infant mortality rate. For outdoor care of poor, the estimated effect was much smaller, with one dollar of per capita spending associated with reducing the infant mortality rate by about 0.08 . Translated to dollars, about $\$ 1.07$ in per capita public health education reduced the infant mortality rate by 1 , while it took $\$ 11.84$ in per capita outdoor care of poor spending to generate this same effect. This further supports the Ewbank and Preston (1989) idea that it was a lack of know-how that led to the poor health outcomes in early twentieth century American cities. Other statistically significant coefficients in the infant mortality equation include those on school spending per pupil (positive), manufacturing wages per worker (negative), the proportion of adults in manufacturing (positive) the proportion of the child bearing population which was black (negative), and city population density (positive). The directions of the coefficients for manufacturing wages, the proportion of adults in manufacturing and city population density are fairly intuitive. Higher average wages tended to decrease infant mortality rates, while a greater proportion of people working in the manufacturing sector tended to increase them. This latter result is very similar to that found by Ruhm (2000), where during periods of lower employment health outcomes improved. The positive coefficient on city population density simply indicates that during the 1920s, the urban penalty still existed and is even identifiable when comparing large urban areas against each other. Cities with greater population densities tended to have poorer infant mortality outcomes. 
It is more surprising that school expenditures per pupil were positively associated with infant mortality. This is an annual variable, so it is unlikely that the inclusion of the illiteracy rates, calculated in the decennial censuses and interpolated, causes the positive result. Additionally, exclusion of the illiteracy variable only attenuates the coefficient to about 0.00912 from the original value of 0.00917 . And the coefficient is still statistically significant, with a p-value of 0.06 . The positive coefficient may indicate that sickness spread more effectively in areas where more children and adults interacted via public schools. It can also be explained if the provision of public education caused fertility to increase disproportionately among the poorer population groups, or those with higher infant mortality.

The negative coefficient on the proportion of the child-bearing population which was black is possibly a result of the fixed effects netting out those factors that led to the poor health outcomes for black populations in the United States. Additionally, during the sample period black migration occurred into the North and out of the South. New York, NY, Philadelphia, PA and Baltimore, MD had the largest percent increases in black populations, while Norfolk, VA, Nashville, TN and Birmingham, AL had the largest percent decreases. While a fully rigorous answer lies beyond the scope of this paper, the negative coefficient may indicate that migrating black families from the South into the North was positively correlated with declines in infant mortality. This could be due to selection from the best and fittest families from these Southern cities, families choosing to migrate into areas with the best possible social services and resources, or perhaps some other factor not considered.

\subsection{Estimating equation for children aged 1 to 4}

The equation which estimates the relationship between child mortality and the investments in the three different public programs is similar to the estimating equation for $I M R^{*}$. The primary difference is in the choice of the lags for the spending variables of interest and the 
included covariates. Additionally, because higher infant mortality in a cohort can affect that cohort's survival chances later in life, whether through selection or a weakening of the individuals, the lagged $I M R^{*}$ is included as well. The estimating equation for the mortality of children aged 1 to 4 is then:

$C D R_{i, t}^{1 t o 4}=\beta_{1} P H E_{i, t-2}+\beta_{2} O C P_{i, t-2}+\beta_{3} C C M_{i, t}+\beta_{3} I M R_{i, t-1}^{*}+\mathrm{BX}+\gamma_{1} C_{i}+\gamma_{2} Y_{t}+\varepsilon_{i, t}$

Where $C D R_{i, t}^{1 t o 4}$ is the crude death rate for children aged 1 to 4 , in this case scaled to reflect the number of child deaths per 10,000 people. $P H E_{i, t-2}$ is, as before, the second lag of public health education spending occurring in city $i^{12} O C P_{i, t-2}$ is the second lag of per capita outdoor care of poor spending in city $i$. Interestingly, in this child mortality regression, it was the second lag of outdoor care of poor which was economically and statistically significant. $C C M_{i, t}$ is current year charity for children and mothers spending. ${ }^{13} I M R_{i, t-1}^{*}$ is the lagged estimate of the infant mortality rate, included to try to control for cohort selection. B is again the vector of coefficients for the matrix $\mathrm{X}$, although in the child mortality regression, with the exception of the number of drought months, the covariates in $\mathrm{X}$ all represent current year values. The errors are assumed to have mean zero, conditional on the covariates in the mortality equations and defined as the unobserved characteristics affecting child mortality in city $i$, year $t$ for each of the different age groups. These are also clustered at the Census region level. $C_{i}$ and $Y_{t}$ are vectors of city and year effects, respectively. Results from this regression are given in Table 6.

Besides the public program variables, other variables significantly related to changes in child mortality included other charitable spending, spending on hospitals, the proportion of

\footnotetext{
${ }^{12}$ See footnote 7

13 See footnote 8
} 
adults in manufacturing, the percent black, percent illiterate, and the number of drought months in the prior year. Both charitable spending other than spending directed towards children and mothers, and spending on hospitals, were positively related to changes in the mortality of children. The positive coefficient on the charitable spending is likely a result of changes in a city's economic conditions more than anything. Spending in this category is dominated by spending towards poor institutions, which experienced an increase in their populations through the 1920s (Smith 1932). The reasons for the disproportionate increase in almshouse population during this period include the boarding of county poor in city almshouses, older men being displaced by industry, fewer multiple generation households and increases in chronic diseases (Smith 1932). These factors which were related to increases in the almshouse populations potentially also contributed to higher mortality among children. In any case, the estimated coefficient is not particularly large. The positive coefficient on hospital expenditures is suggestive of a mortality penalty remaining for hospitals during the 1920s. This is not altogether surprising, as hospitals did not begin to improve health outcomes such as maternal mortality until the 1930s (Thomasson and Treber 2008).

The coefficient on the proportion of adults in manufacturing industries was again positive and statistically significant, as was the coefficient on percent illiterate and the number of months of drought occurring in the preceding year. These coefficients are all fairly intuitive in their direction. Whether due to increased inequality or other factors, higher illiteracy is generally correlated with poorer health outcomes. And a state which was hit hard by drought in the prior year would have higher food prices, thus leading to poorer nutrition. The proportion of the female childbearing population which was black is again negative and statistically significant, perhaps a result of the same factors outlined in the subsection above. The coefficient on the lagged $I M R^{*}$ was not quite statistically significant at the $10 \%$ level; 
however with a p-value of 0.13 , it was close. Its coefficient was also negative, indicating the cohort selection effect where a high infant mortality rate in one year tends to reduce that cohorts' child mortality in the next.

In terms of investment in the three different public programs, expenditures on both public health education and outdoor care of poor were both statistically significantly correlated with reductions in child mortality between 1923 and 1932. Both coefficients are economically significant, however the outdoor care of poor coefficient is a fifth the size of the coefficient for public health education expenditures. From the estimates in Column 2, a dollar spent on per capita public health education in the cities was related to reducing the number of child deaths by about 0.185 points. This indicates that about $\$ 54,000$ public health education dollars were associated with one child aged 1 to 4 life saved. For outdoor care of poor, this value was about $\$ 270,000$. The statistical value of life estimates calculated in Costa and Kahn (2004) for 1940 were about 1 to 1.5 million in 2007 dollars, so compared to these, money allocated to either outdoor care of poor or public health education yielded benefits much greater than the costs. Additionally, it appears that the public health and outdoor care of poor programs saved a statistical life at a much lower cost than New Deal Relief during the 1930s. Converted to 2007 dollars, Fishback, Haines and Kantor (2007) estimated that about $\$ 2.3$ million was the estimated relief cost per infant death prevented. New Deal relief, however, was not specifically targeted at saving infant lives like the public health programs of the 1920s were. The reasons for the differences in the results are likely due to this targeting, and increased opportunities for changes in behavior and hygiene to positively affect health. But while both public health and poverty relief reduced mortality for both infants and children aged 1 to 4 at a good cost-benefit ratio, the spending on public health education resulted in the largest estimated benefits. 


\section{Concluding remarks}

Besides the collecting of birth and death registration certificates and treating cases of malaria and tuberculosis, public health education was the primary method of interaction between state health departments and the public in the early $20^{\text {th }}$ century. During the 1920 s, many different states and cities engaged in educating the public about proper ways to care for infants and how to keep children healthy. Many municipal health departments held "well-child" conferences, set up infant-welfare stations to observe the health of newborns, and sent out bulletins and newspaper press releases. Additionally, other programs formed in the decade prior to the 1920 s continued to administer relief. For families that were temporarily dependent, outdoor care of poor payments provided some relief from unemployment. Mothers' pensions helped out widowed women with children, and some charitable programs helped aid children when their families could not care for them. Also during this period of the 1920s, infant and child mortality rates fell substantially in large U.S. cities. Furthermore, some cities greatly improved their mortality outcomes through the 1920s, while others improved only marginally. This led to a compressing of infant and child mortality across U.S. municipalities.

This paper examined the extent to which these mortality declines and the differing trends across cities can be explained by expanded spending on public health education and poor relief in the 1920s and 1930s. Using a model with city and year fixed effects, the analysis shows that both types of programs contributed to reductions in infant mortality and child mortality, but that it took some time for the effects to be felt. In the case of both infants and children, it took a two year lag for the public health education expenditures to generate an effect.

The fixed effects estimates also indicate that public health education was more cost effective than poverty relief. Cities in the top quartile of public health education spending 
between 1923 and 1932 (about $\$ 4.29$ per capita annually), experienced a faster average annual decline in their infant mortality rates of about 2.5 units relative to cities in the bottom quartile (about $\$ 1.56$ per capita annually). Conversely, cities in the top quartile in outdoor care of poor spending (about $\$ 8.80$ per capita) experienced a faster average annual decline on the level of about .65 points relative to the bottom quartile cities (about $\$ 1$ per capita). Results using the mortality of children aged 1 to 4 are consistent. Adjusted to year 2007 dollars, approximately $\$ 54,000$ spent on public health education was associated with the prevention of a child death. Meanwhile, an additional $\$ 270,000$ in outdoor care of poor spending was associated with the same effect. The estimated effects indicate that both the outdoor care of poor and public health education programs were cost effective ways to reduce infant and child mortality during the 1920s. These cost figures are much lower than those found in modern studies of Medicare expenditures and studies of the impact of work relief during the 1930s.

The results from the models estimated help explain why some U.S. cities entered the 1930s with large improvements in their mortality outcomes, while others saw little improvement in their outcomes over an otherwise prosperous decade. Although prior scholars could not directly measure these changes, they hypothesized that the simple lessons taught by the public health programs were very effective. That changing behaviors and dispersion of knowledge regarding health and hygiene were of primary importance in improving health outcomes in the early twentieth century. The analysis supports the inferences made by Ewbank and Preston (1989) and Preston and Haines (1991) and indicates that education played a large role in the United States' health transition in the early 1900s. And it shows that, while not diminishing the importance of the outdoor care of poor programs, the public health programs instituted prior to the New Deal have been among the most cost effective programs in American history. 


\section{References}

Abbott, Grace, "Federal Aid for the Protection of Maternity and Infancy." American Journal of Public Health, 12 (1922), 737-743.

Brown, Walter H, "The Trend of Maternal and Child Hygiene." American Journal of Public Health, 13 (1923).

Costa, Dora and Matt Kahn, "Changes in the Value of Life 1940-1980." Journal of Risk and Uncertainty, 29 (2004), 159-180.

Cutler, David and Grant Miller, "The Role of Public Health Improvements in Heath Advances: The Twentieth Century United States." Demography, 25 (2005), 1-22.

Department of Commerce, Financial Statistics of Cities, 1923-1932, (Washington D.C.: U.S. Government Printing Office), 1925-1934.

Department of Commerce, Biennial Census of Manufactures, 1923-1933, (Washington D.C.: U.S. Government Printing Office), 1925-1935

Department of Commerce, Mortality Statistics, 1923-1931, (Washington D.C.: U.S. Government Printing Office), 1925-1934

Dempsey, Mary V. Infant Mortality: Results of a Field Study in Brockton, Mass. Based on Births in One Year, Children's Bureau Publication No. 37, (Washington D.C.: U.S. Government Printing Office), 1919.

Duke, Emma, Results of Field Study in Johnstown, PA., Based on Births in One Calendar Year, Children's Bureau Publication No. 9, (Washington D.C.: U.S. Government Printing Office), 1915.

Ewbank, Douglas C. and Samuel H Preston, "Personal Health Behavior and the Decline in Infant and Child Mortality: The United States, 1900-1930," in What We Know About Health Transition: The Cultural, Social and Behavioural Determinants of Health; Proceedings of an International Workshop. Vol. 1.

Ferrell, John A., Wilson G. Smillie, Platt W. Covington, and Pauline A. Mead, eds., Health Departments of States and Provinces of the United States and Canada, (Washington D.C.: U.S. Government Printing Office), 1932.

Fishback, Price V., Michael R. Haines, Shawn Kantor, "Births, Deaths, and New Deal Relief During the Great Depression," The Review of Economics and Statistics, 89 (2007), 114

Fishback, Price V. and Valentina Kachanovskaya, "In Search of the Multiplier for Federal Spending in the States During the Great Depression," NBER Working Paper No. 16561, 2010. 
Fox, Jonathan F. and Mikko Myrskylä, "Urban Fertility Responses to Local Government Programs: Evidence from the 1923-1932 U.S.," MPIDR Working Paper WP-2011-018, 2011.

Haines, Michael R., "The White Population of the United States, 1790-1920," in A Population History of North America, Michael R. Haines and Richard H. Steckel, eds. (New York, NY: Cambridge University Press), 2000.

Hughes, Elizabeth. Infant Mortality: Results of Field Study in Gary, Ind., Based on Births in One Year, Children's Bureau Publication No. 112. (Washington D.C.: U.S. Government Printing Office), 1923.

Martin, Robert F, National Income and Its Distribution, 1919-1938, The Conference Economic Record (September 8, 1939), 81-92.

Meckel, Richard A., Save the Babies, (Baltimore, MD: Johns Hopkins University Press), 1990.

Moehling, Carolyn and Melissa Thomasson, "The Political Economy of Saving Mothers and Babies: The Politics of State Participation in the Sheppard-Towner Program," Working Paper, 2009.

New York State, "Budget of Estimated Expenditures from 1924 Funds for the Period July 1, 1923 to June 30, 1924," Division of Maternity and Infancy, 1924.

Newmayer, S.W., (1911) “The Warfare against Infant Mortality," Annals of the American Academy of Political and Social Science, 37 (1911), 288-298.

Officer, Lawrence H., "The Annual Consumer Price Index for the United States, 1774-2010." MeasuringWorth, 2011 URL: http://www.measuringworth.com/uscpi/, 2011.

Preston, Samuel H. and Michael R. Haines, Fatal Years: Child Mortality in Late NineteenthCentury America. (Princeton, NJ: Princeton University Press), 1991.

Ruhm, Christopher, “Are Recessions Good for Your Health?” Quarterly Journal of Economics, 115 (2000), 617-650.

Skocpol, Theda, and Marjorie Abend-Wein, Christopher Howard, Susan Goodrich Lehmann, "Women's Associations and the Enactment of Mothers' Pensions in the United States," The American Political Science Review, 87 (1993), 686-701.

Thomasson, Melissa A. and Jaret Treber., "From Home to Hospital: The Evolution of Childbirth in the United States, 1928-1940," Explorations in Economic History, 45 (2008),76-99.

Thompson, Stewart G., "Factors that Influence Infant Mortality," American Journal of Public Health, 11 (1921), 415-419.

Troesken, Werner, Water, Race, and Disease, (Cambridge, MA: The MIT Press), 2004 
Turner, C.E., "Health Teaching and the School Health Program," American Journal of Public Health, Vol. 11 (1921).

U.S. Bureau of Internal Revenue, Statistics of Income for 1923-1932, (Washington D.C.: U.S. Government Printing Office), 1925-1934.

U.S. Children's Bureau. The Promotion of the Welfare and Hygiene of Maternity and Infancy, Bureau Publication 137, (Washington D.C.: U.S. Government Printing Office), 1924

U.S. Public Health Service, Public Health Bulletin 136: Report of the Committee on Municipal Health Department Practice, (Washington D.C.: U.S. Government Printing Office), 1923.

U.S. Public Health Service, Public Health Bulletin No. 222: A History of County Health Organizations, (Washington D.C.: U.S. Government Printing Office), 1935

Vincent, George E. The Rockefeller Foundation Annual Report, (New York, NY: The Rockefeller Foundation), 1921. 


\section{Figure 1 \\ 1920 BRA States and DRA Cities over 100k}

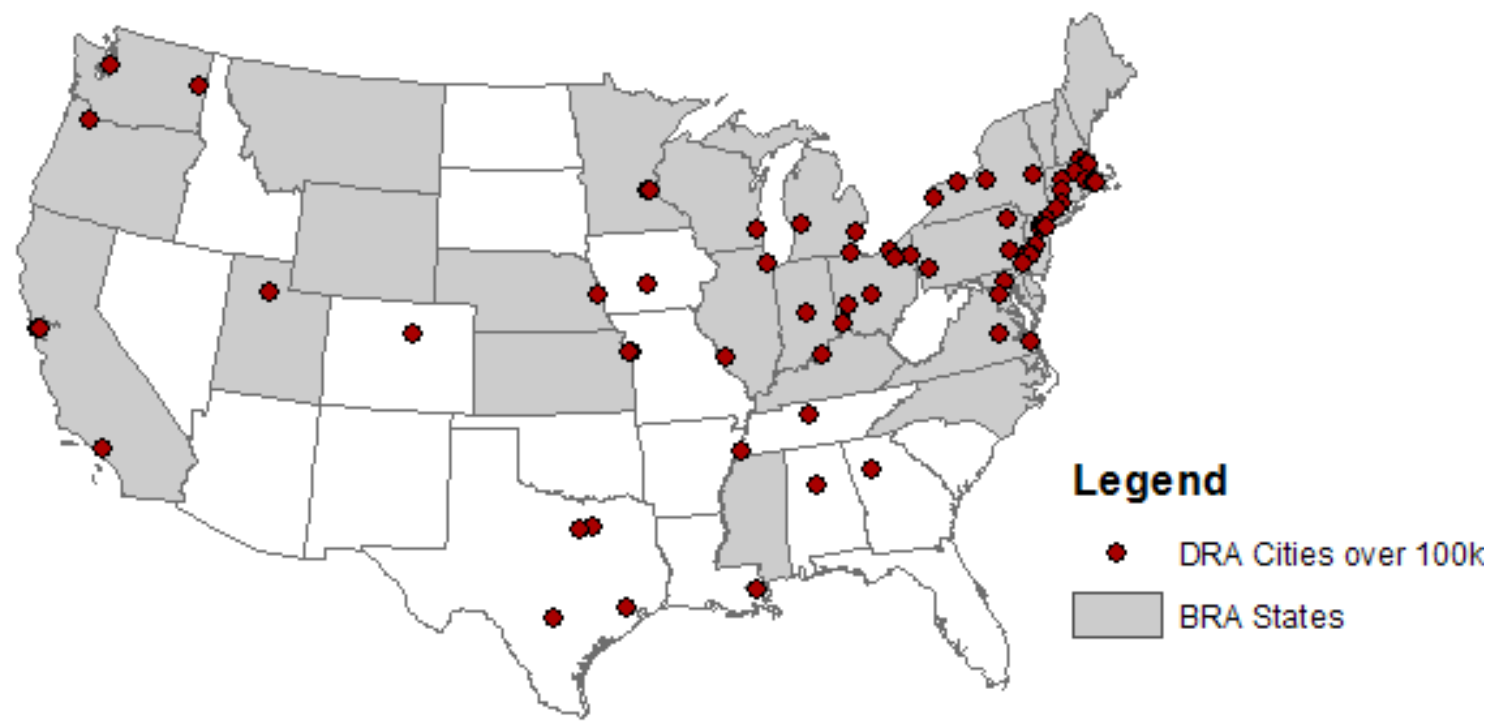

Figure 2

Birth Series: 1920 BRA Cities over 100k Population

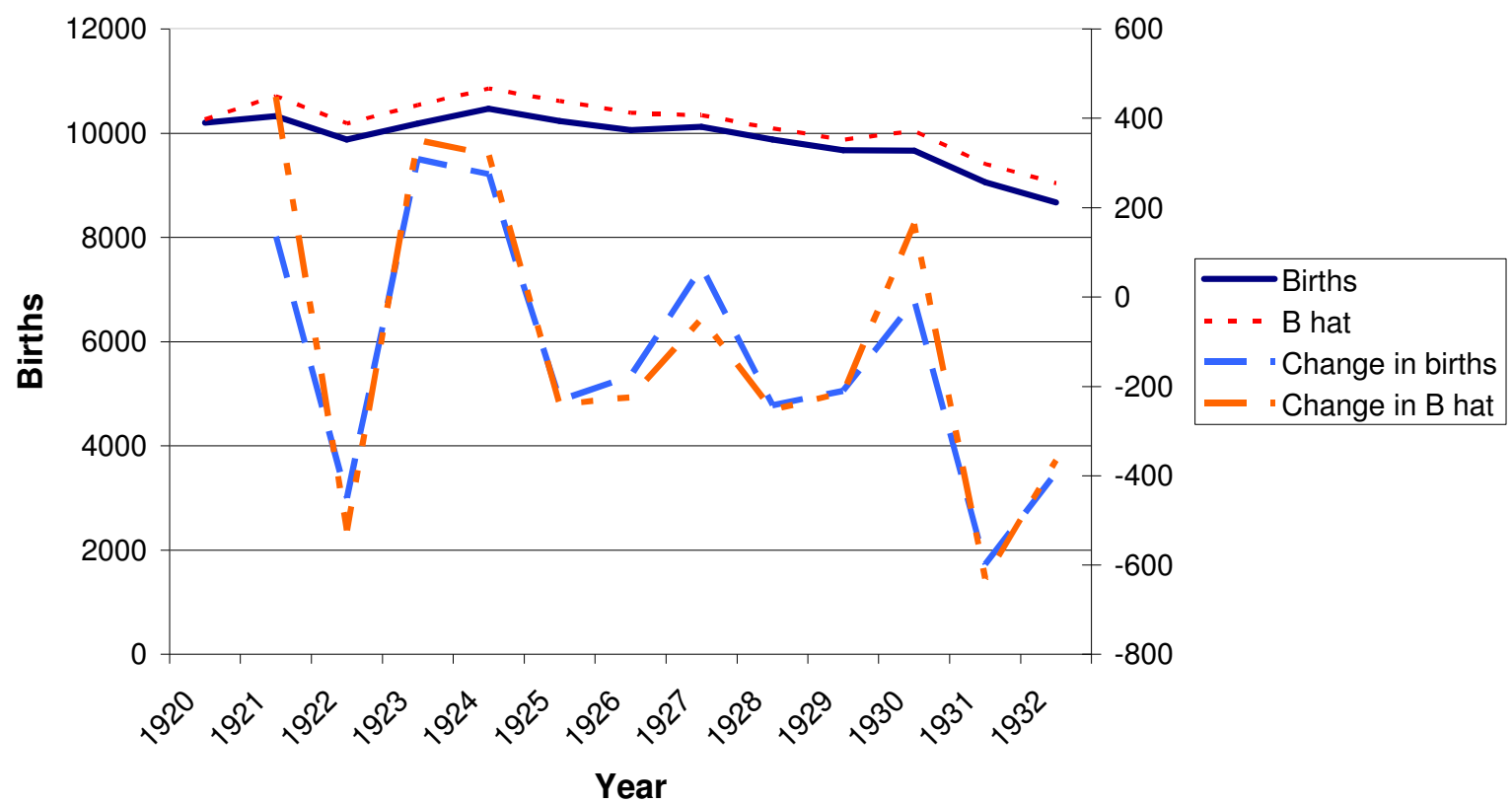




\section{Figure 3}

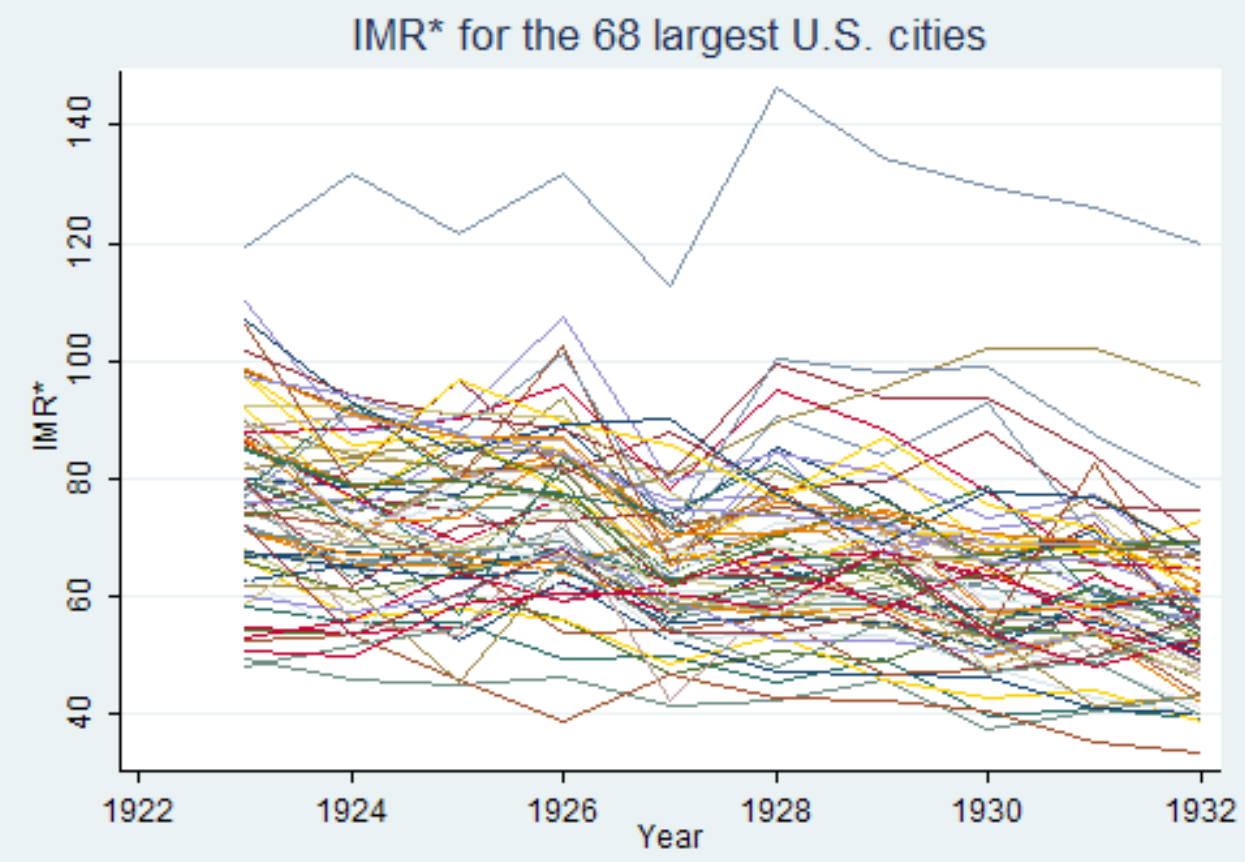

Notes: IMR* is the estimated infant mortality rate as defined in Section 3. The cities included are those over 100,000 persons in 1920

\section{Figure 4}

Age 1 to 4 dths/1,000 persons for the 68 largest U.S. cities

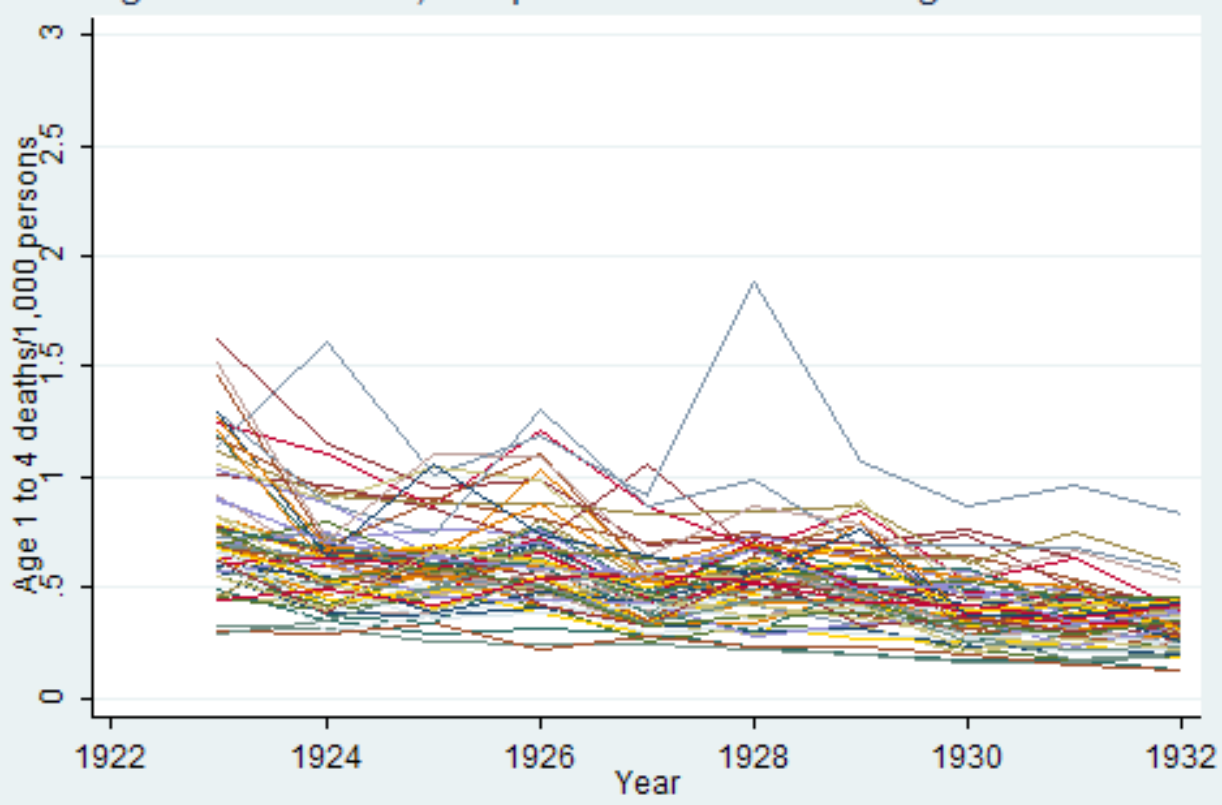

Notes: The cities included are those over 100,000 persons in 1920 


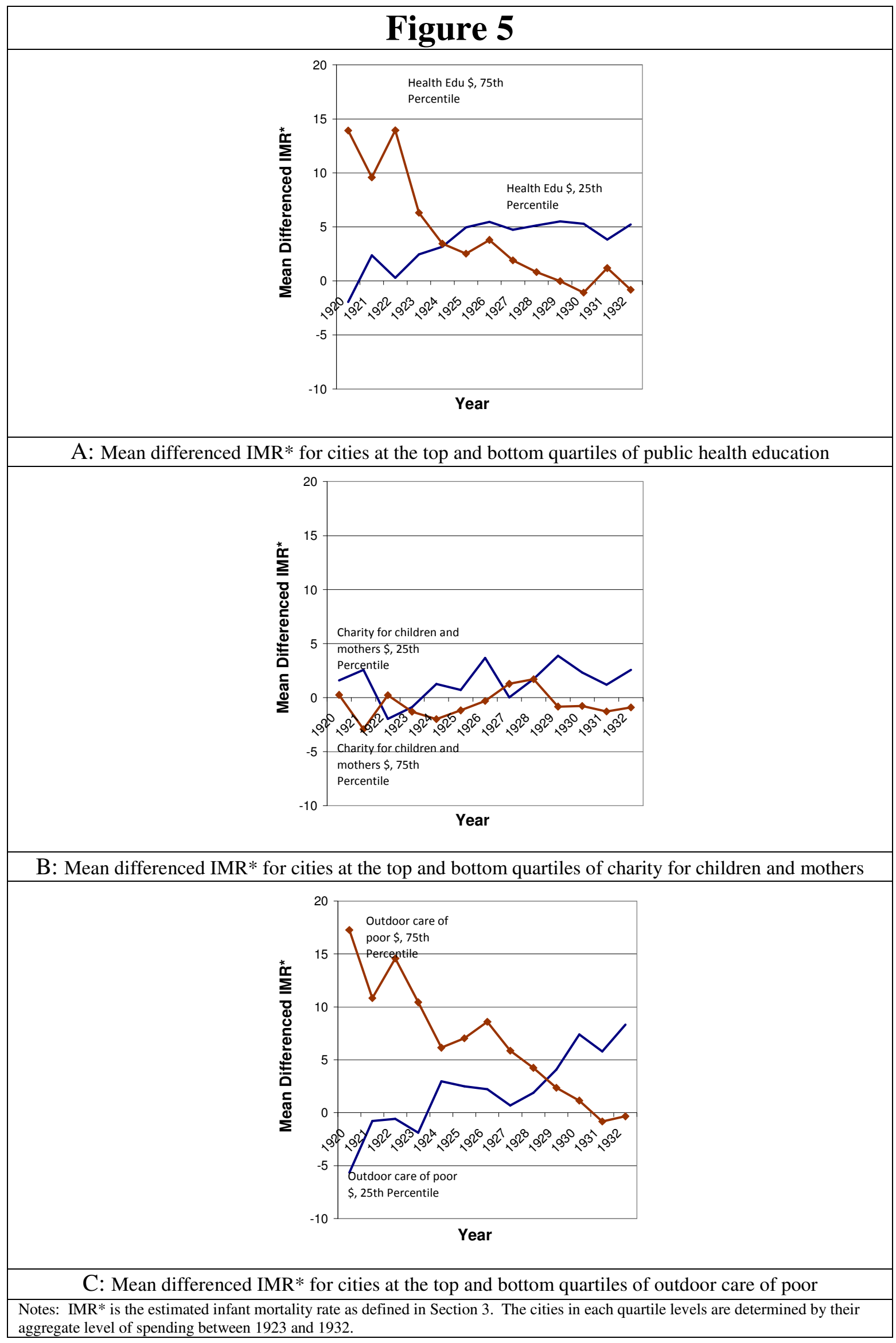




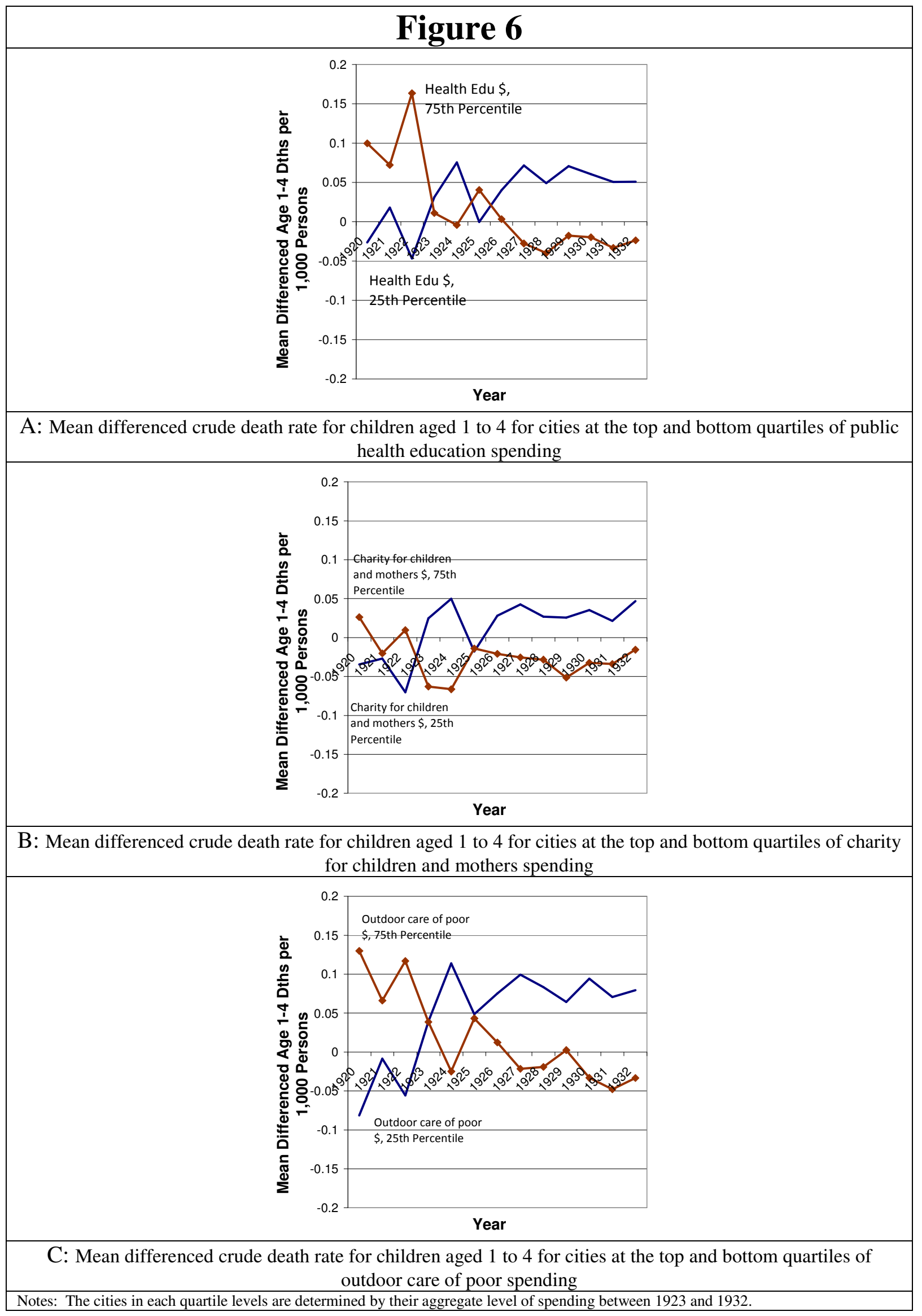




\section{Table 1}

Dep. Var: Annual births

$B$ hat

$0.872457^{* *}$

$(0.0030)$

Constant

$679.964^{\star \star}$

(67.5717)

Observations

605

Adjusted R-squared

0.9929

Standard errors in parentheses

${ }^{* *} p<0.01,{ }^{*} p<0.05,+p<0.1$ 


\section{Table 2}

Summary Statistics

Per Capita Spending Variables

Municipal Spending Variables ${ }^{1}$

Municipal health and welfare spending

Health education

Outdoor care of poor

Charity for children and mothers

Other charity

Other municipal cost payments

Hospitals

Schools (spending per enrolled pupil)

Personal income/Economic outcome variables ${ }^{2}$

Manufacturing wages per worker

Proportion of adults in manufacturing

Population proportion filing taxes

Demographics and environmental ${ }^{3}$

Municipal

For Women Aged 15 to 44

Percent black

Percent foreign born

For persons over 10

Percent illiterate

Other

City population density

Proportion of children under 5

State

Suffrage enacted before 1914

Suffrage enacted between 1915-1919

Suffrage enacted in 1920

Environmental
Mean

$\underline{\text { Min }}$

$\underline{\operatorname{Max}}$

Cities with

no spending

$\$ 3.17$

11.56

4.70

5.51

0.07

12.64

216.36

38.30

49.01

(

0

0

16

9

$\begin{array}{cccc}\$ 10.36 & 0 & 92.14 & 8 \\ 1,057.65 & 363.83 & 2,150.68 & 0\end{array}$

Mean $\quad \underline{\text { Min }} \quad$ Max

$\$ 15,421.77 \quad 10,299.00 \quad 24,370.13$

$17.40 \% \quad 2.41 \% \quad 51.33 \%$

$6.62 \% \quad 1.17 \% \quad 23.46 \%$

$\underline{\text { Mean }} \quad \underline{\text { Min }} \quad \underline{\text { Max }}$

$\begin{array}{ccc}9.54 \% & 0.11 \% & 44.34 \% \\ 15.61 \% & 0.00 \% & 46.50 \%\end{array}$

$3.44 \% \quad 0.51 \% \quad 11.44 \%$

$9,437.87 \quad 1,694.88 \quad 29,388.50$

$8.21 \% \quad 4.89 \% \quad 11.38 \%$

$14.71 \%$

$44.12 \%$

$41.18 \%$

Months of drought within year occuring in state 1.805 11.75

\section{Notes:}

'Source: Financial Statistics of Cities volumes, 1923-1932. All spending variables are in per capita terms and adjusted to 2007 dollars unless 2Source: Manufacturing wages and the percent of manufacturing workers in heavy industry are obtained from the Census of Manufactures volumes, 1923-1933. The number of municipal tax returns are obtained from the Statistics of Income volumes published by the IRS, $1923-1932$. ${ }^{3}$ With the exception of the county population density and suffrage timing, municipal demographics are from the Decennial Censuses and interpolated for the intercensal years. The number of months of drought is from the National Climatic Data Center temperature and precipitation 


\section{Table 4}

Fixed Effects model

Dependent variable:

$\mathrm{IMR}^{*}$

$\mathrm{IMR}^{*}$

Municipal spending variables

Municipal health and welfare spending ${ }^{12}$

Public health education

$\begin{array}{cc}-0.95349^{*} & -0.93216^{*} \\ (0.3089) & (0.3339) \\ -0.08080)_{+} & -0.084468+ \\ (0.0406) & (0.0436) \\ 0.17329)_{+} & 0.16999 \\ (0.0908) & (0.1077)\end{array}$

Other municipal cost payments ${ }^{12}$

0.09542

Other charitable spending

$(0.1821)$

Hospitals (current yr spending)

$-0.00357$

(0.0945)

School spending per pupil (current yr spending)

$0.00917+$

(0.0042)

Personal income/economic outcome variables ${ }^{1}$

Manufacturing wages per worker

$-0.001838^{*}$

(0.0006)

Proportion of adults in manufacturing

$49.2569^{* *}$

(12.6446)

Population proportion filing taxes

26.752

(47.2952)

Demographics and environmental

Municipal

For women aged 15 to 44

Percent black

$-88.2102+$

(42.5496)

Percent foreign born

$-8.531$

(22.8707)

For persons over 10 years old

Percent illiterate

$-15.2611$

$(105.2400)$

Other

City population density

$0.000702+$

State $^{1}$

Months of drought within year

Constant

$74.9441^{* *}$

$84.4478^{\star \star}$

(1.0955)

$(13.1901)$

\begin{tabular}{lcc}
\hline Observations & 544 & 544 \\
Adjusted R-squared & 0.8409 & 0.8471 \\
\hline \hline
\end{tabular}

\section{Notes:}

Standard errors clustered at the Census region level are in parantheses

${ }^{\star *} p<0.01,{ }^{*} p<0.05,+p<0.1$

For cities in which birth data is available, IMR* is the municipal infant mortality rate. In areas where birth

data is not available, it is estimated using information on the female population in the area

and the average birth rate for the other cities in the sample which were part of the Birth

Registration Area. See the data appendix for a full description of the method.

${ }^{1}$ All variables in this category are set at two year lags unless otherwise noted

${ }^{2}$ Government expenditures are per capita unless otherwise noted and adjusted to 2007 dollars 


\section{Table 5}

Fixed Effects model

Dependent variable:

CDR 1 to 4

CDR 1 to 4

Municipal spending variables

Municipal health and welfare spending

Public health education (2 yr lag)

$\begin{array}{cc}-0.17636+ & -0.18466+ \\ (0.0797) & (0.0848) \\ -0.03602^{*} & -0.03707+ \\ (0.0111) & (0.0197) \\ 0.00332 & -0.02346 \\ (0.0139) & (0.0223)\end{array}$

Other municipal cost payments ${ }^{1}$

$0.02568^{*}$

Other charitable spending

$(0.0087)$

Hospitals

$0.01746+$

$(0.0083)$

School spending per pupil

0.00077

$(0.0010)$

Personal income/economic outcome variables

Manufacturing wages per worker

$-0.0000011$

(0.0001)

5.9159 **

Proportion of adults in manufacturing

(1.6202)

Population proportion filing taxes

Demographics and environmental

Municipal

For women aged 15 to 44

Percent black

$-22.9056^{\star}$

(8.9714)

Percent foreign born

For persons over 10 years old

Percent illiterate

Other

City population density

$-0.000012$

$\mathrm{IMR}^{*}$ (1 year lag)

$-0.0182$

(0.0108)

State

Months of drought within year (1 yr lag)

\begin{tabular}{l}
\hline Observations \\
Adjusted R-squared \\
\hline \hline Notes: \\
Standard errors clustered at the Census region level are in parantheses \\
${ }^{* *} p<0.01,{ }^{*} p<0.05,+p<0.1$ \\
The dependent variable is the scaled crude death rate, namely, the number of child deaths \\
per 10,000 persons \\
For cities in which birth data is available, IMR* is the municipal infant mortality rate. In areas where birth \\
data is not available, it is estimated using information on the female population in the area \\
and the average birth rate for the other cities in the sample which were part of the Birth \\
Registration Area. See the data appendix for a full description of the method. \\
${ }^{1}$ Government expenditures are per capita unless otherwise noted and adjusted to 2007 dollars
\end{tabular}




\section{Appendix}

\section{A1. Omitting non-BRA cities}

It is possible that $\hat{B}_{i, t}$ as defined in Section 3 does not do a good job of predicting births in areas for which birth data is not available. While it is not possible to evaluate $\hat{B}_{i, t}$ in these area not part of the BRA, it is possible to limit the analysis in Section 5 to only those cities participating in the Birth Registration Area, thereby allowing the use of the true Infant Mortality Rate as the dependent variable in the estimating equation for infants. Table A1 gives results from such an analysis. By limiting the sample to only those areas part of the Birth Registration Area, the total number of observations is now 494. In the case of the public programs, although the coefficients on both public health education expenditures and outdoor care poor are slightly attenuated, both remain statistically significant at the $10 \%$ level. Additionally, for both public health education and outdoor care of poor, the coefficients were only reduced by about $8 \%$. The coefficient on charity for children and mothers remained not significant. 


\section{Table A1}

Fixed Effects model

Dependent variable:

IMR

IMR

Municipal spending variables

Municipal health and welfare spending ${ }^{12}$

Public health education

$-0.6667+\quad-0.8559+$

(0.331)

$(0.383)$

Outdoor care of poor (1 yr lag)

$-0.06495+$

$-0.0776+$

Charity for children and mothers

$(0.034)$

(0.035)

0.1596

0.1101

(0.092)

(0.100)

Other municipal cost payments ${ }^{12}$

$0.26422+$

Other charitable spending

(0.118)

Hospitals (current yr spending)

0.00994

(0.087)

School spending per pupil (current yr spending)

$0.01058+$

Personal income/economic outcome variables ${ }^{1}$

Manufacturing wages per worker

$-0.001546^{* *}$

$(0.00044)$

Proportion of adults in manufacturing

26.510

$(15.425)$

Population proportion filing taxes

$-9.200$

(38.564)

Demographics and environmental

Municipal

For women aged 15 to 44

Percent black

$-85.3311+$

(45.310)

Percent foreign born

For persons over 10 years old

367.17

Percent illiterate

Other

City population density

$-0.000023$

$(0.000267)$

State ${ }^{1}$

Months of drought within year

Constant

$74.4164^{\star \star}$

$84.2895^{\star \star}$

(1.007)

(10.120)

\begin{tabular}{lcc}
\hline Observations & 494 & 494 \\
Adjusted R-squared & 0.8260 & 0.8303 \\
\hline \hline
\end{tabular}

Notes:

Standard errors clustered at the Census region level are in parantheses

${ }^{* *} p<0.01,{ }^{*} p<0.05,+p<0.1$

For cities in which birth data is available, IMR* is the municipal infant mortality rate. In areas where birth

data is not available, it is estimated using information on the female population in the area

and the average birth rate for the other cities in the sample which were part of the Birth

Registration Area.

${ }^{1}$ All variables in this category are set at two year lags unless otherwise noted

${ }^{2}$ Government expenditures are per capita unless otherwise noted and adjusted to 2007 dollars 


\section{A2. A city specific trend variable}

This section looks at effect of inclusion of a city specific trend variable. Both the models for infants and children as defined in Section 5 are estimated, but with the inclusion of a variable $g_{i, t}$ to control for the different mortality trends within the cities. The inclusion of this variable removes the trend in mortality in each of the different cities, thereby identifying the effect of public health education and poor relief spending off of deviations within that trend.

Coefficient estimates for the infant mortality model are given in Table A2. Column 1 includes only the spending variables of interest, city and year fixed effects and the random trend variable, and Column 2 includes the covariates. Because the demographic variables are linear interpolations between the decennial censuses, they are omitted from the analysis. For this infant mortality analysis, although the point estimates for the coefficients on public health education and outdoor care of poor spending are very similar to those estimated in Table 4, they are no longer statistically significant. Because the model is now identifying off of deviations in the trends, it may be that nearly all of the relevant variation in the public health education variable is absorbed by the trends. In fact, city and year fixed effects control for about 72 percent of the variation in public health education expenditures. Combined with the city specific trend variable, this level is about 93 percent. For outdoor care of poor, the combination of city and year fixed effects and the city specific trend variable controls for about 63 percent of the variation in municipal expenditures. Given the proportion of variance controlled for by the city specific trends, it is not surprising that for at least the infant mortality model, the coefficients on public program expenditures are no longer statistically significant.

Coefficient estimates for the child mortality model are given in Table A3. As was the case in the estimating equation for infants, the point estimates for the coefficients on public 
health education and outdoor care of poor remained relatively unchanged. And while the precision of the coefficient estimates is reduced, the coefficient on public health education expenditures remains significant at the $10 \%$ level.

\section{Table A2}

Fixed effects model with random trend variable

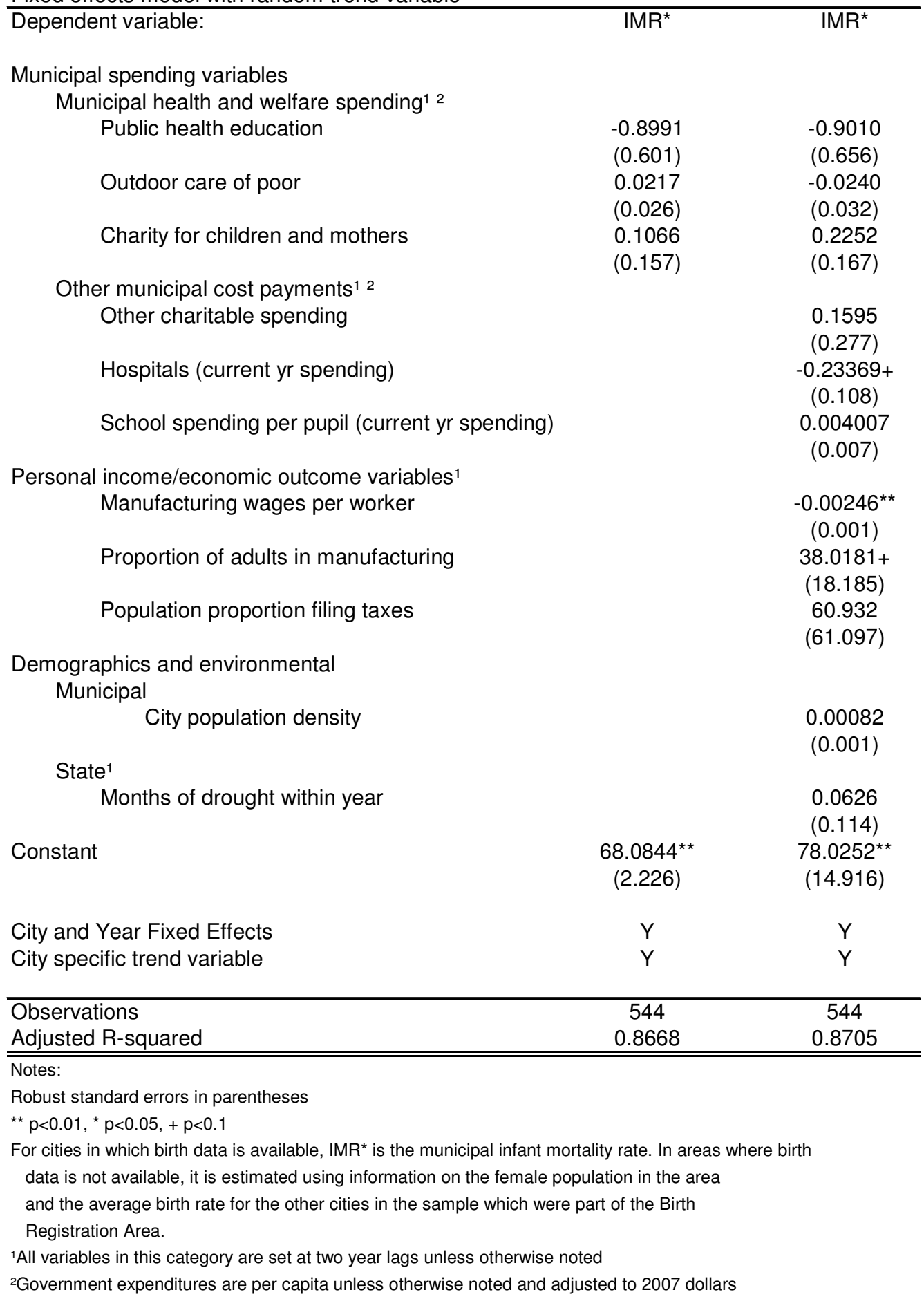




\section{Table A3}

Fixed effects model with random trend variable

Municipal spending variables

Municipal health and welfare spending

Public health education (2 yr lag)

$\begin{array}{cc}-0.1958+ & -0.17259+ \\ (0.102) & (0.081) \\ -0.01673 & -0.03239 \\ (0.020) & (0.024) \\ 0.01856 & 0.01257 \\ (0.021) & (0.020)\end{array}$

Outdoor care of poor ( $1 \mathrm{yr}$ lag)

Charity for children and mothers

$(0.021)$

Other municipal cost payments ${ }^{1}$

Other charitable spending

$0.0335^{\star \star}$

Hospitals

0.01318

(0.014)

School spending per pupil

$-0.00057$

Personal income/economic outcome variables ${ }^{1}$

Manufacturing wages per worker

Proportion of adults in manufacturing

Population proportion filing taxes

Demographics and environmental

Municipal

City population density

$-0.000154$

$\mathrm{IMR}^{\star}$ (1 year lag)

State $^{1}$

Months of drought within year

Constant

City and Year Fixed Effects

City specific trend variable

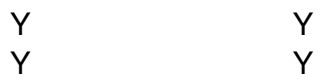

Observations

Notes:

Robust standard errors in parentheses

${ }^{\star *} p<0.01,{ }^{*} p<0.05,+p<0.1$

For cities in which birth data is available, IMR* is the municipal infant mortality rate. In areas where birth data is not available, it is estimated using information on the female population in the area and the average birth rate for the other cities in the sample which were part of the Birth Registration Area.

${ }^{1}$ All variables in this category are set at two year lags unless otherwise noted

${ }^{2}$ Government expenditures are per capita unless otherwise noted and adjusted to 2007 dollars 


\section{A3. Data Notes}

The dataset contains annual information on a set of 68 cities between 1923 and 1932. These are cities over 100,000 persons in 1920 , that being the same cutoff used in the publication for much of the necessary financial and Census data. For a list of those cities which were part of the analysis, see Table A4. Each city is given, along with its entry date into the Birth Registration Area and an indicator for whether it was used in the analysis present in Figure 2.

The start date of 1923 was chosen for data availability reasons. The financial statistics for cities were first published by the Department of Commerce in 1906, however were unfortunately not published in 1920 due to all available Census workers being focused on the 1920 national census. Additionally, in an effort to save costs in 1921 and 1922, the Bureau tried sending out questionnaires to the different cities. Some of the necessary financial detail is missing for those years, and that which exists is of a questionable quality. 1923 was the first year for which there is reliable financial information and the public health programs show up in government outlays.

Manufacturing earnings were entered from the Biannual Census of Manufactures volumes to help control for municipal income. Since the Census of Manufactures was published every other year, state per capita income, estimated by Robert Martin (1939), was used to interpolate. ${ }^{14}$ The interpolation formula used was:

$\mathrm{MW}_{\mathrm{i}, \mathrm{t}}=\mathrm{SPCI}_{\mathrm{t}}\left(\frac{1}{2} \frac{\mathrm{MW}_{\mathrm{i}, \mathrm{t}-1}}{\mathrm{SPCI}_{\mathrm{t}-1}}+\frac{1}{2} \frac{\mathrm{MW}_{\mathrm{i}, \mathrm{t}+1}}{\mathrm{SPCI}_{\mathrm{t}+1}}\right)$,

Where $S P C I_{t}$ is state per capita income in year $t$. The number of workers, also taken from the Biannual Census of Manufactures is used to calculate average annual wages on a per

\footnotetext{
${ }^{14}$ Martin (1939) does not give a good description of how he came to his estimates. Fishback and Kachanovskaya (2010) ran regressions for each state with the BEA state income data as a function of the Martin data without an intercept over the period from 1929 to 1938 when the two sets of series. The R-squareds from each of the regressions were all above 0.98 . When they ran correlations of the growth rates for the overlap periods, they are all over 0.6 and most are over 0.9 .
} 
worker basis. A simple interpolation is used to calculate the number of workers for offcensus years.

In order to calculate population densities, the land area of the different cities was determined from the Decennial Censuses. When information on the land area of a city was missing, it was determined by the next closest date in the future for which the information was available. For instance, if the land area was missing for 1920, the 1930 value was used. If it was missing for 1930 also, then the 1940 value was used, and so on. In most cases the cities did not expand, however there were some exceptions such as Los Angeles, CA.

The financial statistics and manufacturing wages are inflated to 2007 dollars. This was done using the CPI calculations performed by Lawrence Officer (2011) available on the MeasuringWorth website. Although there was very little change in the price index during the first part the 1920s, there was some level of depreciation towards the end and into the early 1930s. 


\section{Table A4}

List of Sample Cities

\begin{tabular}{|c|c|c|c|c|c|c|c|}
\hline & & Year entered & Used in & & & Year entered & Used in \\
\hline City Name & State & BRA & Fig 2 & City Name & State & BRA & Fig 2 \\
\hline Birmingham & $\mathrm{AL}$ & 1927 & & Akron & $\mathrm{OH}$ & 1917 & $\mathrm{x}$ \\
\hline Los Angeles & $\mathrm{CA}$ & 1919 & $\mathrm{x}$ & Cincinnati & $\mathrm{OH}$ & 1917 & $x$ \\
\hline Oakland & $\mathrm{CA}$ & 1919 & $x$ & Cleveland & $\mathrm{OH}$ & 1917 & $x$ \\
\hline San Francisco & $\mathrm{CA}$ & 1919 & $x$ & Columbus & $\mathrm{OH}$ & 1917 & $x$ \\
\hline Denver & $\mathrm{CO}$ & 1928 & & Dayton & $\mathrm{OH}$ & 1917 & $x$ \\
\hline Bridgeport & CT & 1915 & $x$ & Toledo & $\mathrm{OH}$ & 1917 & $x$ \\
\hline Hartford & CT & 1915 & $x$ & Youngstown & $\mathrm{OH}$ & 1917 & $x$ \\
\hline New Haven & CT & 1915 & $x$ & Portland & OR & 1919 & $x$ \\
\hline Washington D.C. & $\mathrm{DC}$ & 1915 & $x$ & Philadelphia & PA & 1915 & $x$ \\
\hline Wilmington & DE & 1921 & & Pittsburgh & PA & 1915 & $x$ \\
\hline Atlanta & $\mathrm{GA}$ & 1928 & & Reading & PA & 1915 & $x$ \\
\hline Chicago & IL & 1922 & & Scranton & PA & 1915 & $x$ \\
\hline Indianapolis & IN & 1917 & $\mathrm{x}$ & Providence & $\mathrm{RI}$ & 1915 & $x$ \\
\hline Des Moines & 10 & 1924 & & Memphis & $\mathrm{TN}$ & 1927 & \\
\hline Kansas City & $\mathrm{KS}$ & 1917 & $x$ & Nashville & $\mathrm{TN}$ & 1927 & \\
\hline Louisville & $\mathrm{KY}$ & 1917 & $x$ & Dallas & $\mathrm{TX}$ & 1933 & \\
\hline New Orleans & LA & 1927 & & Fort Worth & $\mathrm{TX}$ & 1933 & \\
\hline Boston & MA & 1915 & $x$ & Houston & $\mathrm{TX}$ & 1933 & \\
\hline Cambridge & MA & 1915 & $x$ & San Antonio & $\mathrm{TX}$ & 1933 & \\
\hline Fall River & MA & 1915 & $x$ & Salt Lake City & UT & 1917 & $x$ \\
\hline Lowell & MA & 1915 & $x$ & Norfolk & VA & 1917 & $x$ \\
\hline New Bedford & MA & 1915 & $x$ & Richmond & VA & 1917 & $x$ \\
\hline Springfield & MA & 1915 & $x$ & Seattle & WA & 1917 & $x$ \\
\hline Worcester & MA & 1915 & $x$ & Spokane & WA & 1917 & $x$ \\
\hline Baltimore & MD & 1916 & $x$ & Milwaukee & WI & 1917 & $x$ \\
\hline Detroit & MI & 1915 & $x$ & & & & \\
\hline Grand Rapids & MI & 1915 & $\mathrm{x}$ & & & & \\
\hline Minneapolis & MN & 1915 & $x$ & & & & \\
\hline St. Paul & $\mathrm{MN}$ & 1915 & $x$ & & & & \\
\hline Kansas City & MO & 1927 & & & & & \\
\hline St. Louis & MO & 1927 & & & & & \\
\hline Omaha & NE & 1920 & $x$ & & & & \\
\hline Camden & NJ & 1921 & & & & & \\
\hline Jersey City & NJ & 1921 & & & & & \\
\hline Newark & NJ & 1921 & & & & & \\
\hline Paterson & NJ & 1921 & & & & & \\
\hline Trenton & NJ & 1921 & & & & & \\
\hline Albany & NY & 1915 & $\mathrm{x}$ & & & & \\
\hline Buffalo & NY & 1915 & $x$ & & & & \\
\hline New York & NY & 1915 & $x$ & & & & \\
\hline Rochester & NY & 1915 & $x$ & & & & \\
\hline Syracuse & NY & 1915 & $x$ & & & & \\
\hline Yonkers & NY & 1915 & $x$ & & & & \\
\hline
\end{tabular}

Source: Birth, Stillbirth, and Infant Mortality Statistics for the Continental United States,

the Territory of Hawaii, The Virgin Islands: 1933 